\section{Methicillin resistant Staphylococcus aureus}

SIR,-During the past five years a particular strain of methicillin resistant Staphylococcus aureus has been recognised as being epidemic in the Thames regions. ${ }^{12}$ This strain not only can cause serious disease in some groups of patients but has also spread within and between hospitals in spite of attempts to prevent this happening. ${ }^{134}$

Over the past 12 months we have obtained evidence that this organism is spreading outside the Thames regions, and we know of 10 instances where transfer of a patient infected or colonised with epidemic methicillin resistant $S$ aureus has resulted in the first introduction of this strain into a hospital. Transfer of the organism is often associated with patients who have undergone specialised surgical or medical procedures in the London area and may be returning to hospitals distant from the Thames regions.

The introduction of epidemic methicillin resistant $S$ aureus into a hospital is a serious event; its control may involve heavy expenditure and curtailment of clinical services, increased patient morbidity, and even mortality. Goodfield and Littlewood have recorded some of the consequences of a transfer with subsequent spread to dermatology patients. ${ }^{5}$

We strongly advise that thought should be given to the undesirability of transferring patients in this way. If such transfers are necessary patients returning from London should be isolated until they are shown to be free of the organism. Recipient hospitals should be warned by hospitals transferring patients if this methicillin resistant strain is circulating.

E $M$ COOKE R R MARPLES

Division of Hospital Infection,

Central Public Health Laboratory,

Central Public Healt
London NW9 5HT

1 Marples RR, Cooke EM. Report. Workshop on methicillin resistant Staphylococcus aureus held at the headquarters of the Public Health Laboratory Service on 8 January 1985. I Hosp Infect 1985;6:342-8.

2 Marples RR, Richardson JF, de Saxe MJ. Bacteriological characters of strains of Staphylococcus aureus submitted to reference laboratory related to methicillin resistance. $\mathcal{f} H y$ (Camb) 1986;96:217-23.

3 Ayliffe GAJ, et al. Guidelines for the control of epidemic methicillin-resistant Staphylococcus aureus. 7 Hosp Infect 1986; 7:193-201.

4 Shanson DC, Johnstone D, Midgley J. Control of a hospital outbreak of methicillin-resistant Staphylococcus aureus infecoutbreak of methicillin-resistant Staphylococcus aureus infec-
tion: value of an isolation unit. $\mathcal{J}$ Hosp Infect 1985;6:285-92.

5 Goodfield MJD, Littlewood SM. Methicillin resistant Staphylococcus aureus. Lancet 1985; ii:606.

\section{The unremitting burden on carers}

SIR,-Mr Robert Anderson in his concise review of the pressures on people caring for severely disabled people living at home includes among the services required "planned respite care for their charges and free time" (10 January, p 73).

Both of these forms of help require more thoughtful planning than they have had in the past. Respite care needs to be firmly booked months in advance if the carer is to be able to have a holiday with her or his family. The disabled person will be staying in either a "home" or a hospital. If the former he or she should have the opportunity to visit the place beforehand. The staff should be aware of the different needs of short stay residents and long stay residents, whose only home the place may be. Problems of coping with short stay residents in long stay homes have been studied by Allen, ${ }^{1}$ who states, "the idea that short stay care was in any way different from long stay care was clearly one which officers and staff found difficult to cope with and it was a recurrent theme in this research."
If the respite admission is to hospital then the opportunity should be taken to reassess the clinical, functional, and social conditions of the patient and to provide a programme of rehabilitation. Dental inspection and necessary treatment should be included. Respite care should be a helpful and positive episode for the resident or patient as well as providing relief for the carer. Another aspect of the need for temporary care is the emergency admission of the disabled person during illness of the carer or other crisis in the household. Clear decisions have to be taken by health and social services managers about its provision, and general practitioners must be informed about the arrangements.

"Free time" for carers can be provided by various schemes of relief staff or visitors coming to the person's home and by the disabled person attending day centres or day hospitals. Confusion about the functions of the centres and hospitals and transport problems continue to make many of these facilities less effective than they should be. ${ }^{2-4}$ Each district health authority should be reviewing the totality of its services for severely disabled people along the lines set out in the two recent reports of the Royal College of Physicians and doing this in conjunction with the local social services department, voluntary bodies, and representatives of disabled people and their carers. ${ }^{56}$ Many aspects of respite and day care need reviewing if "community care" is to avoid overburdening the many people who are truly working or on call 24 hours a day, every day of each year, in ignorance of when their responsibilities will end and without the option of resigning or retiring.

Canterbury, Kent CT4 5AZ

MiChaEL WARREN

1 Allen I. Short-stay residential care for the elderly. London: Policy Studies Institute, 1983.

Carter J. Day services for adults. London: George Allen and Unwin, 1981.

3 Martin A, Millard PH. Day hospitals for the elderly: therapeutic or social? London: Geriatric Teaching and Research Unit, S George's Hospital, 1978 .

4 Brocklehurst JC, Tucker JS. Progress in geriatric day care. London: King Edward's Hospital Fund for London, 1980.

Royal College of Physicians. Physical disability in 1986 and beyond. London: Royal College of Physicians, 1986.

6 Royal College of Physicians. The young disabled adult. The use of residential homes and hospital units for the age group 16-64 London: Royal College of Physicians, 1986.

\section{Snoring as a risk factor for ischaemic heart} disease and stroke in men

SIR,-Dr Markku Koskenvo and colleagues (3 January, p 16) state that snoring is related to obstructive sleep apnoea and that these patients may develop hypoxaemia and hypercapnia, together with increased pulmonary and systemic arterial pressure. They later speculate that low oxygen saturation has an unfavourable effect on the activity of lipoprotein receptors, leading to increased serum low density lipoprotein concentrations; the role of thrombocyte aggregation and coronary artery spasm in sleep apnoea is also unclear. At no point do they mention the effect of hypoxia on the haemoglobin concentration or whether there was any significant difference in the haemoglobin concentration, packed cell volume, or blood viscosity between the various groups.

Intermittent hypoxia has been shown to cause polycythaemia in animal studies, ${ }^{1}$ and hypoxia during sleep is thought to be an important determinant of the degree of secondary polycythaemia in patients with chronic obstructive airways disease. $^{2-4}$ Hypoxia increases the packed cel volume through two different mechanisms. Firstly, it causes a release of erythropoietin from the kidney, which then causes an increase in the red cell mass (a true polycythaemia). Secondly, hypoxia, both acute and chronic, can cause a contraction of the plasma volume (pseudopolycythaemia) through mechanisms which are poorly understood but possibly related to increased adrenergic activity and venoconstriction. ${ }^{5}$ In some patients both of these factors, increased red cell mass and reduced plasma volume, are present.

An increased packed cell volume, from whatever cause, is itself associated with an increased incidence of both ischaemic heart disease ${ }^{6-9}$ and cerebrovascular disease, ${ }^{9-11}$ thought to be due to its effect on the viscosity of blood. Several studies have shown that cerebral blood flow is reduced in patients with a high packed cell volume and can be improved by reducing the packed cell volume..$^{12}$ It is unfortunate that the authors do not mention the packed cell volume or haemoglobin concentration of their patients, even if only to state that there was no significant difference between the habitual snorers and the non-snorers, since they regard the intermittent hypoxia as the key to the increased incidence of arteriovascular disease in these patients. It would also be of interest to know if other risk factors such as enhanced coagulation or decreased fibrinolysis could be shown in the habitual snorers.

Department of Haematology

P YATES

Southmead Hospital

Bristol BS10 5NB

1 Moore-Gillon JC, Cameron IR. Right ventricular hypertrophy and polycythaemia in rats after intermittent exposure hypoxia. Clin Sci 1985;69:595-9.

2 Stradling JR, Lane DJ. Development of secondary poly cythaemia in chronic airways obstruction. Thorax 1981;36: 321-5.

3 Flenley DC. Clinical hypoxia: causes, consequences, and correction. Lancet 1978; i:542-6.

4 Nocturnal Oxygen Therapy Trial Group. Continuous or nocturnal oxygen therapy in hypoxaemic chronic obstructive lung disease? Ann Intem Med 1980;93:391-8.

5 Isbister JP. Contracted plasma volume syndromes. International Joumal of Microcirculation: Clinical Experimentation 1984;3 93-108.

6 Burch GE, de Pasquale NP. The haematocrit in patients with myocardial infarction. JAMA 1962;180:63-5.

7 Lowe DGO, Drummond MM, Lorimer AR, et al. Relation between extent of coronary heart disease and blood viscosity. Angiology 1979;30:594-9.

8 Nicholaides AN, Bowers R, Horbourne T, Kidner PH, Besterman EM. Blood viscosity, red-cell flexibility, haematocrit and plasma fibrinogen in patients with angina. Lancet 1977 ;ii: plasm-5.

9 Cullen KJ, Stenhouse NS, Wearne KL. Raised haemoglobin and risk of cardiovascular disease. Lancet 1981;ii: 1288-9.

10 Harrison MJG, Kendall BE, Pollock S, Marshall J. Effect of haematocrit on carotid stenosis and cerebral infarction. Lancet 1981;ii:114-5.

11 Kannel WB, Gordon T, Wolf PA, McNamara P. Haemoglobin and the risk of cerebral infarction: the Framingham study Stroke 1972;3:409-20.

12 Thomas DJ, Marshall J, Russell RWR, et al. Effect of haem tocrit on cerebral blood-flow in man. Lancet 1977;ii:941-3.

13 Humphrey PRD, Michael J, Pearson TC. Management of relative polycythaemia: studies of cerebral blood flow and viscosity. Br J Haematol 1980;46:427-33.

\section{Association between liberalisation of Scotland's liquor licensing laws and admissions for self poisoning}

SIR,-In our paper (6 December, p 1466) we did not seek to attribute the sharp and immediate increase in the percentage of patients taking alcohol with their overdose to changes in the Scottish licensing laws alone, as the percentage of women taking alcohol was increasing slowly before 1976 . Pace Drs S P Lockhart, J H Baron, and Stephen Platt (10 January, p 116), we still believe, however, that the sharp and immediate rise which occurred in the two years after the change in the law justified our suggestion that there was likely to be a direct relation between these two facts. Our clinical data on poisoned patients have been under consistent and detailed review over the past 17 years and we 
could find no other major social or environmental change that occurred in the population we served which might have explained these striking findings.

We agree with Dr Platt that it would have been advantageous to compare our experience with that of similar districts in England. Despite strenuous efforts, however, we could not obtain comparable data of this type. The experience in the Edinburgh poisons unit has apparently been different from our own, but several factors may explain this. In contrast to our own policy during the period of study, we understand that in Edinburgh, particularly during the latter years of the review described by Dr Platt, the admission policy has changed in that only some of the patients reaching the accident and emergency department are admitted to the poisoning centre. Also, from the data presented, it is clear that the percentage of Edinburgh patients who took alcohol with their overdose before the change in the licensing laws was more than twice that in our own series. This may well have obscured and at least reduced any impact which the change in the law may have caused in the Edinburgh admission rate. As far as poisoning is concerned, it is well established that patients from capital cities and other dense conurbations behave differently from those is a mixed urban and rural community.

We would suggest, therefore, that the data presented by Dr Platt are not necessarily strictly comparable with our own. Clearly it is difficult to provide any proof of the association which we suggested and we would be most interested to learn of others' experience, particularly from comparable district general hospitals.

A Lawson JOHN MCMURRAY D B NORTHRIDGE

Milesmark Hospital,

Rumblingwell

Dunfermline KY12 9NR

\section{Manpower}

SIR,-We recently received the communication from the chairmen of the Central Committee for Hospital Medical Services and the Hospital Junior Staff Committee about hospital medical staffing. We are worried about the implications of the report Achieving a Balance and feel that agreements have been reached on our behalf with which we are not in accord. The consultation process adopted by the BMA leadership has not successfully informed the leaders of what their members think.

The circular attempting to explain Achieving a Balance leaves many questions unanswered.

(1) Why is there such a need to rush into restructuring junior hospital doctors' jobs?

(2) How can expansion of the consultant grade be accommodated "within existing facilities"? How can a surgeon operate without theatre space or without an anaesthetist? How can a physician run a clinic when there is no clinic space?

(3) What is the good of simply shifting the bottleneck in junior posts down to senior house officer grade? The competition for hospital SHO posts and for vocational training scheme posts is already bad enough.

(4) The BMA has not explained how a reduction in quality of patient care can be avoided in those districts in which there is a reduction in numbers not only of registrars but also of SHOs and senior registrars. In one paragraph the crucial service role of the registrar is acknowledged, yet the basis of this report is that the numbers of registrar posts should be reduced.

(5) How is it possible to avoid creating two types of registrar who provide different levels of care? Distric registrar posts will be essential for service needs, but is it right for the National Health Service to depend on supply of foreign graduates on short term contracts?

(6) Will not the new intermediate service grade simply consist of part trained consultants ill supported by resources (secretary, office, junior staff) who will be expected to do the real consultants' night duty for them?

(7) Has anyone considered the wisdom of a system which effectively abolishes all competition above SHO grade? Future consultants will be chosen within two or three years of graduation, long before their suitability for such posts can be assessed.

(8) Does the BMA understand the problems implicit in a reduction in clinical research? The distinction drawn between training in research methods and in clinical research is nonsense. To suggest that a research registrar should be drawn from the overall quota of acute service registrars is also nonsenseunless there are to be more registrars allocated than there is clinical work to be done.

In summary, we are deeply disturbed about both the fundamental principles and the details of this report. We believe the solutions proposed for the problems of the hospital medical career structure are ill considered. We suggest, moreover, that the whole problem has been approached in the wrong way. Matching the number of registrar posts to the expected number of consultant vacancies is a very blinkered way of planning medical staffing of the health service. How much better to begin by matching the numbers of the different grades of staff to the work to be done. Then we might know whether the system could support a pyramidal career structure without undue wastage or whether a wholesale change in this historic pattern might be better.

Achieving a Balance may solve some of the problems of medical career structure but as a package deal we believe it has so many flaws that it would be best to reject it completely and to have no deal at all.

\section{A Morgan and W JefFcoate} and 104 other doctors

City, General, and University Hospitals,

Nottingham

Neurological and neurosurgical approaches in the management of malignant brain tumours

SIR,-In our original paper (18 October, $p$ 1015) we perhaps did not make it clear that the 18 cases in the text referred only to those of a proved glioma (excluding ependymoma) for the diagnosis of malignant glioma was certainly not proved in the remaining cases, which were also recorded in table V. Certainly the great majority of patients submitted to radiotherapy had undergone surgery, but in most cases this was a burr hole biopsy alone.

There is no evidence to support the contention that patients who did not undergo surgery included a greater proportion with low grade tumours or no tumours than the group who underwent biopsy. Indeed, as judged by the other criteria the groups were broadly similar.

Mr D G T Thomas and others (10 January, $p$ 123) correctly quote from the discussion in Salcman's paper, ${ }^{1}$ but the data in that paper showed that the median survival in glioblastoma multiforme was 4 months with operation alone and 9.25 months when radiotherapy was added. Whether this represents an improvement other than marginal, once time has been allowed for treatment and its effects, is a matter of opinion.

$\mathrm{Mr}$ Thomas and his colleagues quote the trial of Walker $e t a l^{2}$ as one in which steroids alone were used in one arm. Ninety five per cent of patients admitted to that trial had undergone a major resection, and all had to have a projected survival of at least two months postoperatively and to have received steroids for less than one month before they could be admitted to one of the four arms of that trial. Only $76 \%$ of the patients actually received any steroids. This cannot therefore be said to constitute a trial of steroid therapy in an unselected series of patients.

The other papers ${ }^{3-5}$ quoted by Mr Thomas $\stackrel{\square}{\complement}$ and others and by Dr C E Fadul and others $C$ (p 1015) concern randomisation of patients who $\widehat{\Omega}$ had survived major surgery for two to four weeks $\overline{\bar{J}}$ and who were "fit enough" to withstand radiotherapy or chemotherapy. The criteria for major $\mathbb{\&}$ surgery were not given and we do not know what $m$ happened to those who did not undergo major resection. The patients admitted to these surgical trials were, as Dr Fadul and colleagues acknow- $\frac{\rho}{9}$ ledge, a different cohort from those assessed in our $\overline{0}$ clinical audit. Each trial showed that radiotherapy $\frac{C}{\sigma}$ did prolong life in these selected cases and that any $\bar{\omega}$ additional effect of chemotherapy was marginal. $\vec{\nabla}$ Indeed, each paper pleaded for a more effective $\varrho$ management regimen.

We would emphasise again that our report was a $\vec{\circ}$ clinical audit of an unselected group of patients presenting consecutively to different consultants $\overrightarrow{\vec{\omega}}$ in a regional neurosciences unit. Many of the $\stackrel{\omega}{\sigma}$ patients would not have been considered suitable $\frac{}{7}$ for entry into the surgical series discussed by your 3 correspondents. This does not mean that we refuse to pursue an aggressive management policy in $\triangle$ those patients in whom this is appropriate. Un- $O$ fortunately such patients represent an all too small proportion of the population presenting to us. $\dot{\omega}$ We will, as we have in the past, continue to join multicentre trials, usually in conjunction with our $\dot{o}$ colleagues in radiotherapy and oncology.

Mersey Regional Department of

Medical and Surgical Neurology,

Walton Hospital,

Liverpool L9 1AE

1 Salcman M. Survival in glioblastoma multiforme: historical perspective. Neurosurgery 1980;7:435-9.

2 Walker MD, Alexander E Jr, Hunt WE, et al. Evaluation of $\mathrm{BCNU}$ and/or radiotherapy in the treatment of anaplastic gliomas. I Neurosurg 1978;49:333-43.

3 Walker MD, Green SB, Byar DP, et al. Randomized comparisons of radiotherapy and nitrosoureas for the treatment of malignant $\mathbb{Q}$ glioma after surgery. $N$ Engl f Med 1980;303:1323-9.

4 Kristiansen K, Hagen S, Kollevold T, et al. Combined modality $\overrightarrow{\vec{O}}$ therapy of operated astrocytomas grade III and IV. Confirma-윽 tion of the value of postoperative irradiation and lack of 3 potentiation of bleomycin on survival time: a prospective $\bar{Z}$ potentiation of bleomycin on survival time: a prospective Group. Cancer 1981; 47:649-52.

5 Green SB, Byar DP, Walker MD, et al. Comparisons of carmustine, procarbazine and high-dose methylprednisolone as additions to surgery and radiotherapy for the treatment of malignant glioma. Cancer Treat Rep 1983;67:121-32.

** This correspondence is now closed.-ED, $B M \mathcal{~}$.

\section{Dialysis arthropathy: amyloid or iron?}

SIR,-We investigated 10 patients undergoing regular haemodialysis treatment (duration 4-180 years) who underwent a carpal tunnel release operation (bilateral in two patients). The synovia tissue was histologically examined for iron, aluminium, amyloid, and $\beta_{2}$ microglobulin. Of these eight had amyloid and their synovial tissue stained positively for $\beta_{2}$ microglobulin using an immuno peroxidase method. Aluminium was not detected in any of these specimens, and only one patient had? deposits of haemosiderin but her serum ferritim concentration was $39 \mu \mathrm{g} / \mathrm{l}$. Another patient who was anephric had received 130 units of blooof transfusions; her serum ferritin concentration was $8030 \mu \mathrm{g} / \mathrm{l}$ and she showed no evidence of iron in the synovial tissue. However, in this patient excess iron was present at the osteoid mineralisatiog 